\title{
Role of Chest in Respiratory Distress of Neonates
}

\author{
${ }^{1}$ Nikhil Mehta, ${ }^{2}$ Pratapsingh Parihar, ${ }^{3}$ Saherish Khan, ${ }^{4}$ Garima Rajimwale
}

\begin{abstract}
Introduction: The initial diagnosis of an infant with respiratory distress is crucial as life-saving measures can be started immediately. Despite all the improved diagnostic modalities out there, a roentgenogram of the chest is still considered the most reliable diagnostic tool to establish respiratory distress. The aim of this study was to assess and evaluate the role of chest X-ray $(\mathrm{CXR})$ in neonatal respiratory distress.
\end{abstract}

Materials and methods: This study was a prospective correlational hospital-based study done in 300 neonates in Acharya Vinobha Bhave Rural Hospital, Sawangi (Meghe), Wardha. The neonates who were clinically diagnosed having respiratory distress were evaluated using chest radiograph. In all these patients, the chest radiography findings were noted and correlated with clinical findings.

Results: Transient tachypnea of the newborn (TTNB) was the most common cause of respiratory distress (35.7\%). Chest radiography had the highest sensitivity and specificity in pneumothorax (PTX), tracheoesophageal fistula, lobar emphysema, and diaphragmatic hernia $(100 \%)$. Followed by pneumonia, radiography had $81.2 \%$ sensitivity and $86.5 \%$ specificity; for hyaline membrane disease (HMD), sensitivity and specificity were 80 and $89 \%$ respectively; for meconium aspiration syndrome (MAS), sensitivity was 60.5 and specificity was $81.7 \%$; and for TTNB, sensitivity was $36.4 \%$ and specificity was $96 \%$. Overall diagnostic accuracy was $59.7 \%$, i.e., the final clinical diagnosis confirmed by CXR.

Conclusion: A chest radiograph has high sensitivity for congenital diaphragmatic hernia (CDH), PTX, congenital lobar emphysema, tracheoesophageal fistula, pneumonia, and HMD and low sensitivity for TTNB. To sum up, a plain chest radiograph is an indispensable tool in neonates with respiratory distress, but as with any diagnostic modality, it has its own limitations.

Keywords: Chest X-ray, Diagnostic role, Respiratory distress of newborn.

How to cite this article: Mehta N, Parihar P, Khan S, Rajimwale G. Role of Chest in Respiratory Distress of Neonates. Int J Recent Surg Med Sci 2018;4(1):19-23.

Source of support: Nil

Conflict of interest: None

\footnotetext{
1,3,4 Resident, ${ }^{2}$ Professor

${ }^{1}$ Department of Radiology, Jawaharlal Nehru Medical College Sawangi (Meghe), Wardha; Acharya Vinoba Bhave Rural Hospital, Sawangi (Meghe), Wardha Maharashtra, India

${ }^{2-4}$ Department of Radiodiagnosis, Jawaharlal Nehru Medical College, Wardha, Maharashtra, India

Corresponding Author: Nikhil Mehta, Resident, Department of Radiology, Jawaharlal Nehru Medical College, Sawangi (Meghe) Wardha; Acharya Vinoba Bhave Rural Hospital, Sawangi (Meghe), Wardha, Maharashtra, India, Phone: +919765063000 e-mail: mehta.liberated@gmail.com
}

\section{INTRODUCTION}

Successful adaptation to breathing at the time of birth is the culmination of an orderly process of pulmonary cell growth and differentiation, leading to alveolar and capillary surfaces capable of providing oxygen and eliminating carbon dioxide. Failure to achieve adequate gas exchange at birth represents respiratory distress which is a major cause of perinatal morbidity and mortality. ${ }^{1}$

The initial diagnosis of an infant with respiratory distress is crucial, as life-saving measures can be started immediately. This fortifies the need for an efficient tool to reinforce a clinical suspicion. Despite all the improved diagnostic modalities out there like ultrasonography, computed tomography (CT) scan, and magnetic resonance imaging, a roentgenogram of the chest is still considered the most reliable diagnostic tool to establish respiratory distress ${ }^{2}$ and is indicated if any infant exhibits the signs. A plain CXR is not only affordable but also widely available and easily executable. Therefore, a plain CXR continues to be the primary mode of imaging for diagnosis.

The outcome of respiratory distress has a devastating impact on the families of the infants, as it usually results in either death or a lifelong disability, with a significant $7 \%$ of the newborns diagnosed with respiratory distress. ${ }^{3}$

In this study, the role of CXR in the diagnosis of medical and surgical causes of respiratory distress was studied. An analysis was also carried out to see in which situations an X-ray would not help in the diagnosis so that we could study the role of a CT scan in such situations.

\section{MATERIALS AND METHODS}

This study was a prospective correlational hospitalbased study done in 300 neonates in the department of radio diagnosis, in a tertiary hospital between August 2014 and August 2016. The neonates who were clinically diagnosed having respiratory distress were evaluated using chest radiograph. In all these patients, the chest radiography findings will be noted and correlated with clinical findings. Computed tomography thorax was performed wherever recommended and feasible to confirm the diagnosis. Those neonates whose families were not willing for inclusion in the study, neonates presenting with cardiovascular causes of respiratory distress, 
neonates presenting with systemic causes of respiratory distress were excluded.

\section{X-ray Equipment}

The radiographs for the study were performed on a portable Siemens Multimobil Series 2.5 X-ray machine. The machine has a tube potential of 40 to $125 \mathrm{kVp}$, exposure time of $20 \mathrm{~ms}$ to $5 \mathrm{~s}$, and source to floor distance of 70 to $200 \mathrm{~cm}$. The system uses a single film screen combination.

\section{Technique of Chest Radiograph in Neonates}

The emphasis was on high quality and low exposure in keeping with the As Low As Reasonably Achievable principle and collimation included:

- The beam should be centered at the nipple line and collimated to the outer chest.

- Superiorly: At the level of the chin; nothing above this level should be irradiated.

- Inferiorly: Above the level of the umbilicus.

- Laterally: To include the lateral chest walls.

\section{Patient Positioning}

Neonatal chest radiographs were taken in the anteroposterior view and a relative held the neonate.

\section{Statistical Analysis}

Statistical analysis was done using descriptive and inferential statistics using test statistics: Sensitivity, specificity, positive predictive value (PPV), negative predictive value (NPV), and accuracy. The software tools used in the analysis were Statistical Package for the Social Sciences version 17.0 and GraphPad Prism 6.0 version. Microsoft Word and Excel were used to generate graphs, tables, etc.

\section{RESULTS}

A total of 164 males and 136 females with respiratory distress were admitted in the neonatal intensive care unit (NICU). We found that there was a dominance of males with respiratory distress in our study (Table 1).

Table 2 shows the treatment given in neonates with respiratory distress admitted in NICU. Continued positive airway pressure was given in 226 (75.3\%) cases and antibiotics were given in 107 (35.6\%) cases. Vasopressors were given in $29(9.6 \%)$ cases. Ventilated neonates were $88(29.3 \%)$, followed by surfactant therapy to $54(18 \%)$ cases, and blood transfusion was given in $8(2.66 \%)$ neonates. Surfactant was solely used in the neonates with HMD. Rest of the results of our study are shown in Tables 3 to 9

Table 1: Distribution of patients according to sex

\begin{tabular}{llllllll}
\hline Sex & HMD $(n=64)$ & MAS $(n=48)$ & TTNB $(n=107)$ & PNE $(n=35)$ & PTX $(n=30)$ & SUR $(n=16)$ & Total \\
\hline Male & $36(56.2 \%)$ & $27(56.2 \%)$ & $58(54.2 \%)$ & $15(42.9 \%)$ & $18(60 \%)$ & $10(62.5 \%)$ & $164(54.7 \%)$ \\
Female & $28(43.8 \%)$ & $21(43.8 \%)$ & $49(45.8 \%)$ & $20(57.1 \%)$ & $12(40 \%)$ & $6(37.5 \%)$ & $136(45.3 \%)$ \\
\hline
\end{tabular}

PNE: Pneumonia; SUR: Surgical causes of respiratory distress include congenital cystic adenoid malformation, congenital diaphragmatic hernia, congenital lobar emphysema, pulmonary sequestration, and tracheoesophageal fistula

Table 2: Distribution of patients according to type of treatment

\begin{tabular}{llllllll}
\hline Type of treatment & $H M D(n=64)$ & MAS $(n=48)$ & TTNB $(n=107)$ & PNE $(n=35)$ & PTX $(n=30)$ & SUR $(n=16)$ & Total \\
\hline CPAP & $22(34.4 \%)$ & $34(70.8 \%)$ & $102(95.3 \%)$ & $33(94.3 \%)$ & $20(66.7 \%)$ & $15(93.7 \%)$ & $226(75.3 \%)$ \\
Ventilation & $45(70.3 \%)$ & $9(18.8 \%)$ & $18(16.8 \%)$ & $14(40 \%)$ & $1(3.3 \%)$ & $1(6.3 \%)$ & $88(29.3 \%)$ \\
Inotrops & $23(35.9 \%)$ & $4(8.3 \%)$ & $0(0 \%)$ & $0(0 \%)$ & $2(6.6 \%)$ & $0(0 \%)$ & $29(9.6 \%)$ \\
Antibiotic & $11(17.2 \%)$ & $21(43.7 \%)$ & $35(32.7 \%)$ & $32(91.4 \%)$ & $8(26.7 \%)$ & $0(0 \%)$ & $107(35.6 \%)$ \\
Surfactant & $54(84.4 \%)$ & $0(0 \%)$ & $0(0 \%)$ & $0(0 \%)$ & $0(0 \%)$ & $0(0 \%)$ & $54(18 \%)$ \\
Transfusion & $4(6.3 \%)$ & $2(4.2 \%)$ & $0(0 \%)$ & $1(2.9 \%)$ & $1(3.3 \%)$ & $0(0 \%)$ & $8(2.66 \%)$ \\
\hline
\end{tabular}

PNE: Pneumonia; SUR: Surgical causes of respiratory distress include congenital cystic adenoid malformation, congenital diaphragmatic hernia, congenital lobar emphysema, pulmonary sequestration, and tracheoesophageal fistula; CPAP: Continuous positive airway pressure

Table 3: Chest X-ray findings of pleura

\begin{tabular}{lllllll}
\hline & & Pleura & \\
\hline CXR findings of lungs & HMD $(n=64)$ & MAS $(n=48)$ & TTNB $(n=107)$ & PNE $(n=35)$ & $P T X(n=30)$ & SUR $(n=16)$ \\
\hline Normal & $64(100 \%)$ & $39(81.2 \%)$ & $82(76.7 \%)$ & $19(54.3 \%)$ & $0(0 \%)$ & $16(100 \%)$ \\
PTX & $0(0 \%)$ & $0(0 \%)$ & $0(0 \%)$ & $0(0 \%)$ & $30(100 \%)$ & $0(0 \%)$ \\
Pleural effusion & $0(0 \%)$ & $9(18.8 \%)$ & $10(9.3 \%)$ & $13(37.1 \%)$ & $0(0 \%)$ & $0(0 \%)$ \\
Hydro PTX & $0(0 \%)$ & $0(0 \%)$ & $0(0 \%)$ & $0(0 \%)$ & $0(0 \%)$ & $0(0 \%)$ \\
Lamellar effusion & $0(0 \%)$ & $0(0 \%)$ & $0(0 \%)$ & $0(0 \%)$ & $0(0 \%)$ & $0(0 \%)$ \\
Interlobar fluid & $0(0 \%)$ & $0(0 \%)$ & $15(14.0 \%)$ & $3(8.6 \%)$ & $0(0 \%)$ & $0(0 \%)$ \\
\hline
\end{tabular}

PNE: Pneumonia; SUR: Surgical causes of respiratory distress include congenital cystic adenoid malformation, congenital diaphragmatic hernia, congenital lobar emphysema, pulmonary sequestration, and tracheoesophageal fistula 
Role of Chest in Respiratory Distress of Neonates

\begin{tabular}{lllllll}
\hline \multicolumn{7}{c}{ Table 4: Pulmonary opacities on chest radiograph for each clinical diagnosis } \\
\hline \multicolumn{7}{c}{ Pulmonary opacities } \\
\hline CXR findings of lungs & $H M D(n=64)$ & MAS $(n=48)$ & TTNB $(n=107)$ & PNE $(n=35)$ & $P T X(n=30)$ & SUR $(n=16)$ \\
\hline None & $12(18.7 \%)$ & $17(35.4 \%)$ & $68(63.5 \%)$ & $7(20 \%)$ & $24(80 \%)$ & $15(93.7 \%)$ \\
Reticulogranular pattern & $10(15.6 \%)$ & $5(10.4 \%)$ & $0(0 \%)$ & $4(11.4 \%)$ & $0(0 \%)$ & $0(0 \%)$ \\
Ground glass opacity & $29(45.3 \%)$ & $0(0 \%)$ & $0(0 \%)$ & $0(0 \%)$ & $0(0 \%)$ & $0(0 \%)$ \\
Linear streaking opacity at hilum & $0(0 \%)$ & $0(0 \%)$ & $39(36.4 \%)$ & $0(0 \%)$ & $0(0 \%)$ & $0(0 \%)$ \\
Coarse patchy infiltrates & $5(7.8 \%)$ & $26(54.1 \%)$ & $0(0 \%)$ & $19(54.3 \%)$ & $6(20 \%)$ & $1(6.3 \%)$ \\
Diffuse haziness & $8(12.5)$ & $0(0 \%)$ & $0(0 \%)$ & $5(14.3 \%)$ & $0(0 \%)$ & $0(0 \%)$ \\
\hline
\end{tabular}

PNE: Pneumonia; SUR: Surgical causes of respiratory distress include congenital cystic adenoid malformation, congenital diaphragmatic hernia, congenital lobar emphysema, pulmonary sequestration, and tracheoesophageal fistula

Table 5: Follow-up scan after 72 hours of onset of respiratory distress

\begin{tabular}{|c|c|c|c|c|c|c|}
\hline CXR findings of lungs & $H M D(n=64)$ & $M A S(n=48)$ & $\operatorname{TTNB}(n=107)$ & $P N E(n=35)$ & $P T X(n=30)$ & $\operatorname{SUR}(n=16)$ \\
\hline Normal & $12(18.7 \%)$ & $14(29.2 \%)$ & 77 (71.9\%) & $6(17.1 \%)$ & $5(16.7 \%)$ & $4(25.0 \%)$ \\
\hline $\begin{array}{l}\text { Improvement in lung aeration } \\
\text { and vascular definition with } \\
\text { decreased lung opacities }\end{array}$ & $31(48.4 \%)$ & $22(45.8 \%)$ & $30(28.1 \%)$ & $9(25.7 \%)$ & $6(20 \%)$ & $0(0 \%)$ \\
\hline $\begin{array}{l}\text { Worsening of the disease or } \\
\text { similar appearance }\end{array}$ & $20(31.2 \%)$ & $12(25 \%)$ & $0(0 \%)$ & $17(48.6 \%)$ & $0(0 \%)$ & $7(43.7 \%)$ \\
\hline PTX & $4(6.2 \%)$ & $6(12.5 \%)$ & $0(0 \%)$ & $10(28.6 \%)$ & $19(63.3 \%)$ & $0(0 \%)$ \\
\hline Pulmonary hemorrhage & $5(7.8 \%)$ & $0(0 \%)$ & $0(0 \%)$ & $0(0 \%)$ & $0(0 \%)$ & $0(0 \%)$ \\
\hline Pleural effusion & $0(0 \%)$ & $0(0 \%)$ & $0(0 \%)$ & $0(0 \%)$ & $0(0 \%)$ & $0(0 \%)$ \\
\hline Not performed & $0(0 \%)$ & $1(2.1 \%)$ & $0(0 \%)$ & $0(0 \%)$ & $0(0 \%)$ & $5(31.3 \%)$ \\
\hline
\end{tabular}

PNE: Pneumonia; SUR: Surgical causes of respiratory distress include congenital cystic adenoid malformation, congenital diaphragmatic hernia, congenital lobar emphysema, pulmonary sequestration, and tracheoesophageal fistula

Table 6: Distribution of patients based on accuracy of CXR in diagnosis of patients

\begin{tabular}{|c|c|c|c|}
\hline Disease & $\begin{array}{l}\text { Final } \\
\text { clinical } \\
\text { diagnosis }\end{array}$ & $\begin{array}{l}\text { Clinical } \\
\text { diagnosis } \\
\text { confirmed } \\
\text { by CXR }\end{array}$ & $\begin{array}{l}\text { Accuracy } \\
\text { (\%) }\end{array}$ \\
\hline HMD & 64 & 44 & 68.8 \\
\hline MAS & 48 & 26 & 54.2 \\
\hline $\begin{array}{l}\text { Transient tachypnea of } \\
\text { neonates }\end{array}$ & 107 & 39 & 36.4 \\
\hline Pneumonia & 35 & 26 & 74.3 \\
\hline PTX & 30 & 30 & 100 \\
\hline $\mathrm{CDH}$ & 7 & 7 & 100 \\
\hline $\begin{array}{l}\text { Congenital lobar } \\
\text { emphysema }\end{array}$ & 3 & 3 & 100 \\
\hline $\begin{array}{l}\text { Congenital cystic adenoid } \\
\text { malformation }\end{array}$ & 1 & 0 & 0 \\
\hline Tracheoesophageal fistula & 4 & 4 & 100 \\
\hline Pulmonary sequestration & 1 & 0 & 0 \\
\hline Total & 300 & 179 & 59.6 \\
\hline
\end{tabular}

Table 8: Distribution of patients based on accuracy of CXR and CT scan

\begin{tabular}{|c|c|c|c|c|}
\hline Disease & $\begin{array}{l}\text { Diagnosis } \\
\text { confirmed } \\
\text { by CT }\end{array}$ & $\begin{array}{l}\text { Diagnosis } \\
\text { confirmed } \\
\text { by CXR }\end{array}$ & $\begin{array}{l}\text { Accuracy } \\
\text { of X-ray } \\
(\%)\end{array}$ & $\begin{array}{l}\text { Accuracy } \\
\text { of CT (\%) }\end{array}$ \\
\hline $\begin{array}{l}\text { Congenital lobar } \\
\text { emphysema }\end{array}$ & 3 & 2 & 66.6 & 100 \\
\hline $\begin{array}{l}\text { Congenital } \\
\text { cystic adenoid } \\
\text { malformation }\end{array}$ & 1 & 0 & 0 & 100 \\
\hline $\begin{array}{l}\text { Tracheoesophageal } \\
\text { fistula }\end{array}$ & 4 & 4 & 100 & 100 \\
\hline $\begin{array}{l}\text { Pulmonary } \\
\text { sequestration }\end{array}$ & 1 & 0 & 0 & 100 \\
\hline Total & 9 & 6 & 66.7 & 100 \\
\hline
\end{tabular}

Table 7: Sensitivity and specificity of chest radiograph to diagnose cause of respiratory distress

\begin{tabular}{lllll}
\hline Disease & $\begin{array}{l}\text { Sensitivity } \\
(\%)\end{array}$ & $\begin{array}{l}\text { Specificity } \\
(\%)\end{array}$ & $\begin{array}{l}\text { PPV } \\
(\%)\end{array}$ & $\begin{array}{l}\text { NPV } \\
(\%)\end{array}$ \\
\hline HMD & 80 & 89 & 62 & 95.2 \\
MAS & 60.5 & 81.7 & 35.6 & 92.5 \\
TTNBs & 36.4 & 96 & 100 & 73.9 \\
Pneumonia & 81.2 & 86.5 & 41.9 & 97.4 \\
PTX & 100 & 100 & 100 & 100 \\
CDH & 100 & 100 & 100 & 100 \\
Congenital lobar & 100 & 100 & 100 & 100 \\
$\begin{array}{l}\text { emphysema } \\
\text { Congenital cystic }\end{array}$ & 0 & 100 & 0 & 99.7 \\
$\begin{array}{l}\text { adenoid malformation } \\
\text { Tracheoesophageal }\end{array}$ & 100 & 100 & 100 & 100 \\
fistula & & & & \\
Pulmonary sequestration & 0 & 100 & 0 & 99.7 \\
\hline
\end{tabular}

\section{DISCUSSION}

In the present study, it was seen that $54.7 \%$ of the newborns who developed respiratory distress were males compared with $45.3 \%$ females. This was in accordance with a study done by Lureti et $\mathrm{al}^{4}$ which showed the frequency of neonatal respiratory distress was higher in males when compared with females. Similarly, Assogba et $\mathrm{al}^{5}$ showed that of the 177 patients in the NICU with respiratory distress syndrome (RDS), 99 were males and 78 were females. Miller ${ }^{6}$ similarly showed that the incidence of respiratory distress was almost 3 times higher among males than females.

Out of 300 cases identified with respiratory distress, the commonest cause for respiratory distress was TTNB 
Table 9: Distribution of patients according to type of outcome

\begin{tabular}{llllllll}
\hline Type of outcome & HMD $(n=64)$ & MAS $(n=48)$ & TTNB $(n=107)$ & PNE $(n=35)$ & PTX $(n=30)$ & SUR $(n=16)$ & Total \\
\hline Normal and discharged & $31(48.4 \%)$ & $26(54.2 \%)$ & $107(100 \%)$ & $18(51.4 \%)$ & $19(63.3 \%)$ & $3(18.7 \%)$ & $204(68 \%)$ \\
Worsening of disease & $12(17 \%)$ & $10(20.8 \%)$ & $0(0 \%)$ & $7(20 \%)$ & $0(0 \%)$ & $0(0 \%)$ & $29(9.7 \%)$ \\
Death & $21(32.8 \%)$ & $12(25 \%)$ & $0(0 \%)$ & $9(25.7 \%)$ & $11(36.7 \%)$ & $0(0 \%)$ & $53(17.7 \%$ \\
Referred to higher center & $0(0 \%)$ & $0(0 \%)$ & $0(0 \%)$ & $1(2.9 \%)$ & $0(0 \%)$ & $13(81.3 \%)$ & $14(4.6 \%)$ \\
\hline
\end{tabular}

PNE: Pneumonia; SUR: Surgical causes of respiratory distress include congenital cystic adenoid malformation, congenital diaphragmatic hernia, congenital lobar emphysema, pulmonary sequestration, and tracheoesophageal fistula

seen in 107 cases (35.7\%) followed by HMD in 64 cases $(21.3 \%)$, MAS in 48 cases $(16 \%)$, pneumonia in 35 cases $(11.7 \%)$, PTX in 30 cases $(10 \%)$, and surgical causes of respiratory distress in 16 cases $(5.3 \%)$. Similar results were seen in the study done by Gouyon et $\mathrm{al}^{7}$ where the commonest cause for respiratory distress in newborns was TTNB (72\%), followed by MAS (61\%) and RDS (38\%). Hermansen and Lorah ${ }^{8}$ similarly found that TTNB is the most common cause of neonatal respiratory distress, constituting more than $40 \%$ of cases and suggested that a detailed history is critical for proper evaluation. However, in a study done by Nagendra et al, ${ }^{9}$ the commonest cause for respiratory distress in neonates was RDS (18.8\%) followed by TTNB (14\%) and MAS (12.5\%). This variability in the present study was due to increased number of cesarean deliveries during the study period, giving rise to more number of TTNB cases. Another study done by Sarvaiya et $\mathrm{al}^{10}$ stated that the commonest cause of respiratory distress in neonates was TTNB $(32.20 \%)$, which was followed by HMD (20.33\%), neonatal pneumonia (16.94\%), MAS $(11.86 \%)$, cardiac causes $(5.08 \%)$, tracheoesophageal fistula (4.23), and diaphragmatic hernia (2.54\%).

In the present study, abnormal CXR findings were seen in $66 \%$ cases and were more in HMD (17.3\%), TTNB (13\%), MAS (11.33\%), pneumonia $(9.7 \%)$, and $\mathrm{CDH}(2.3 \%)$. This was significant in early diagnosis for a newborn in respiratory distress. Studies done by MacDonald and Seshia ${ }^{1}$ identified the usefulness of $\mathrm{X}$-ray in neonatal respiratory distress in 89 cases. They observed that an abnormal chest radiogram was seen more in MAS (30.2\%), followed by HMD (29.2\%), PTX $(2.2 \%)$, and $\mathrm{CDH}(1.12 \%)$. This variability in the present study was due to a larger sample size and more number of TTNB (107) cases.

In the present study, the sensitivity and specificity of the radiography in HMD were 80 and $89 \%$ respectively, and in MAS, the sensitivity and specificity were 60.5 and $81.7 \%$. This correlates to the findings of Kurl et $\mathrm{al}^{11}$ study in which clinical and radiographic diagnosis in HMD matched in $95 \%$ of cases. Shahri et al ${ }^{12}$ observed that in 39 patients of HMD, the sensitivity and specificity were 35 and $82 \%$ respectively. This variability in the present study was due to a bigger sample size and also due to interobserver variation in interpretations.
In TTNB cases, the sensitivity and specificity of radiographic tests were 36.4 and $96 \%$ respectively. This is similar to the study of Kurl et $\mathrm{al}^{11}$ in which $48 \%$ of clinical and radiographic diagnosis matched properly. Similarly, Agrawal et $\mathrm{al}^{13}$ found that many newborn with transient tachypnea had clear chest films and that the concept of TTNB should be expanded to include cases with normal chest films. Also the study of Ponhold ${ }^{14}$ revealed that the diagnosis of TTNB is mainly based on clinical signs and symptoms.

The sensitivity and specificity of the CXR in pneumonia were 81.2 and $86.5 \%$ respectively, in the present study. Similarly, Shahri et $\mathrm{ll}^{12}$ found that for pneumonia, radiography had $73 \%$ sensitivity and $87 \%$ specificity.

The specificity and sensitivity of the radiography in diagnosing PTX were $100 \%$. The findings were in accordance with a similar study done by Marini et $\mathrm{al}^{2}$ in which all patients with PTX were diagnosed on CXR.

In this study, congenital lobar emphysema was seen in three cases of which two cases had left upper lobe involvement and one case had right upper lobe involvement and all cases were diagnosed on chest radiograph. However, CT scan thorax was recommended in a doubtful case of right upper lobe congenital lobar emphysema. Similarly, in a study by Salih and Al-Saad, ${ }^{15}$ congenital lobar emphysema was seen in two patients, both affecting the left upper lobe and the appearance was characteristic. Similar findings were observed in studies done by Mhiri et $a 1^{16}$ and Ozcelic et a ${ }^{17}$ which concluded that all cases of congenital lobar emphysema can be seen on chest radiographs.

In this study, $4(1.3 \%)$ cases of tracheoesophageal fistula was diagnosed on chest radiogram. The use of CT thorax was only limited to confirming the type of tracheoesophageal fistula, and all the cases were of type C. Similarly, in a study done by Sarvaiya et al, ${ }_{10}^{10} 5(4.23 \%)$ neonates were diagnosed with tracheoesophageal fistula, $4(80 \%)$ were diagnosed with esophageal atresia with tracheoesophageal fistula between distal end of esophagus and trachea (type C) and $1(20 \%)$ with (type B) only esophageal atresia with no stomach air shadow seen.

For $\mathrm{CDH}$ and congenital lobar emphysema, the sensitivity and specificity of radiographic tests were $100 \%$. Similarly, in a study by Marini et $\mathrm{al}^{2}{ }^{2}$ all cases of hernia were confirmed by radiographs. 
In the present study, in cases of congenital cystic adenoid malformation and pulmonary sequestration, a chest roentgenogram was inconclusive. These were confirmed by a multidetector computed tomography (MDCT) scan thorax. Similarly, Elhamd et al ${ }^{18}$ stated that MDCT was problem solving in complicated cases in whom the simpler tests were inconclusive. It was found that MDCT was useful in confirming the presence of the lesion, determining the extent of the lesion, and defining the associated abnormalities in all our cases which include congenital lobar emphysema and congenital pulmonary airway malformation. Similarly, Donnelly et $\mathrm{al}^{19}$ stated that in cases with unclear diagnosis, CT often provides diagnostic information about the exact anatomic location of the lesion that is difficult to determine on chest radiography.

In our study, 54 neonates with HMD were treated with surfactant and improvement was seen on chest radiograph in 31 patients $(57.4 \%)$, which is comparable to studies done by Dinger et $\mathrm{al}^{20}$ who reported the radiologic findings in 110 neonates treated with exogenous surfactant for established RDS. Uniform improvement was demonstrated on posttreatment chest radiographs in 38\% of the infants, asymmetric improvement in 35\%, no improvement in 10\%, and interstitial gas in $17 \%$.

There was a $17.7 \%$ mortality rate in our study and the most common cause was HMD (7\%), MAS (4\%), PTX $(3.7 \%)$, and pneumonia (3\%). Shrivastava et $\mathrm{al}^{21}$ studied 1,000 babies and found that the most common respiratory cause of neonatal death was birth asphyxia (44\%) followed by RDS $(4.4 \%)$ and MAS $(1.9 \%)$. This variation in the present study was due to the exclusion of extrapulmonary causes of respiratory distress.

\section{REFERENCES}

1. MacDonald, MG.; Seshia, MM. Avery's neonatologypathophysiology and management of the newborn. 7th ed. Philadelphia (PA): Wolters Kluwer; 2016. p. 400-428, 922-950.

2. Marini C, Bulleri A, Cambi L, Marinari A, Bernardini M, Bartalena L, Falaschi F. The neonatal respiratory insufficiency syndrome: the role of the chest radiograph. Radiol Med 1997 Nov;94(5):463-467.

3. Reuter S, Moser C, Baack M. Respiratory distress in the newborn. Pediatr Rev 2014 Oct;35(10):417-428, quiz 429.

4. Lureti M, Parazzini F, Agarossi A, Bianchi C, Rocchetti M, Bevilacqua G. Risk factors for respiratory distress syndrome in the newborn: a multicenter Italian survey. Acta Obstet Gynecol Scand 1993 Jul;72(5):359-364.
5. Assogba K, Kombaté D, Balogou K, Balaka B, KapitanGnimdu M, Gnonlonfoun DD. Acute respiratory distress syndrome of the newborn: the experience of neonatal intensive care unit. J Clin Neonatol 2014 Nov;3(4):239.

6. Miller HC. Respiratory distress syndrome of newborn infants: statistical evaluation of factors possibly affecting survival of premature infants. Pediatrics 1998;573-579.

7. Gouyon JB, Ribakovsky C, Ferdynus C, Quantin C, Sagot P, Gouyon B; Burgundy Perinatal Network. Severe respiratory disorders in term neonates. Paediatr Perinat Epidemiol 2008 Jan;22(1):22-30.

8. Hermansen CL, Lorah KN. Respiratory distress in the newborn. Am Fam Physician 2007 Oct;76(7):987-994.

9. Nagendra K, Wilson CG, Ravichander B, Sood S, Singh SP. Incidence and etiology of respiratory distress in newborn. Med J Armed Forces India 1999 Oct;55(4):331-333.

10. Sarvaiya K, Singla H, Patel N, Dhillon JI, Patel B. Radiological evaluation of neonatal thoracic lesions in 118 neonates. IAIM 2015 Jun;2(6):172-182.

11. Kurl S, Heinonen KM, Kiekara O. The first chest radiograph in neonates exhibiting respiratory distress at birth. Clin Pediatr 1997 May;36(5):285-289.

12. Shahri HM, Naghibi S, Mahdavi E, Khademi G. Diagnostic utility of chest X-rays in neonatal respiratory distress: determining the sensitivity and specificity. Int J Pediatr 2014 Nov;2(4.2):65-72.

13. Agrawal V, David RJ, Harris VJ. Classification of acute respiratory disorders of all newborns in a tertiary care center. J Natl Med Assoc 2001 Jul;95(7):583-595.

14. Ponhold W. Radiological signs of transient tachypnoea and its differential diagnosis (author's transl). Rontgenblatter 1981 Oct;34(10):375-378.

15. Salih FD, Al-Saad RH. Chest radiographic finding in neonatal dyspnea. Al-Kindy Col Med J 2008;4(2):40-44.

16. Mhiri R, Chaabouni M, Loulou F, Ben Salah M, Turki H, Mahfoudh A, Karray A, Nouri A, Triki A. Congenital lobar emphysema. Eight case reports. Tunis Med 2003 Jan;38-47.

17. Ozcelik U, Gocmen A, Kiper N, Dogru D, Dilber E, Yalcin EG. Congenital lobar emphysema: evaluation and long-term follow up of thirty cases at a single center Pediatr Pulmonol, 35(2003), pp. 384-391.

18. Elhamd EA, Seifeldein GS, AbdelAziz NH. Multidetector computed tomography evaluation in neonatal respiratory distress: clinical implication. Egypt J Radiol Nucl Med 2013 Mar;44(1):101-111.

19. Donnelly LF, Frush DR. Localized radiolucent chest lesions in neonates: causes and differentiation. AJR Am J Roentgenol 1999 Jun;172(6):1651-1658.

20. Dinger J, Schwarze R, Rupprecht E. Radiological changes after therapeutic use of surfactant in infants with respiratory distress syndrome. Pediatr Radiol 1997 Jan;27(1):26-31.

21. Shrivastava SP, Kumar A, Ojha AK. Verbal autopsies determined cause of death. Indian Pediatr 2001;38:1022-1025. 